DOI 10.15421/4220011

УДК 519.63

І. В. Гарькавський, Л. І. Книш, д-р техн. наук

\title{
МОДЕЛЮВАННЯ ЕНЕРГОПЕРЕНОСУ В ФАЗОПЕРЕХІДНОМУ ТЕПЛОАКУМУЛЯТОРІ СОНЯЧНОЇ ТЕРМОДИНАМІЧНОЇ УСТАНОВКИ
}

Проведено числове дослідження процесів фазового переходу «тверде тіло - рідина» в тепловому акумуляторі сонячної термодинамічної установки. В основі математичної моделі та числового алгоритму покладено метод "Mushy Layer", який відображає фізичну суть явища. Комп'ютерне моделювання задачі Стефана дозволило виявити особливості процесу фазового переходу, визначити розподіл температур в рідкій та твердий фазі, товщину твердої та рідкої фаз теплоакумулюючого матеріалу, швидкість руху границі розподілу фаз.

Ключові слова: тепловий акумулятор; задача Cmeфрана; метод «Mushy Layer»; теплоакумулюючий матеріал, числові експерименти.

Вступ. Дослідження систем акумулювання теплової енергії є однією із актуальних проблем сучасної енергетики. Ця проблема стає особливо гострою у зв'язку з широким впровадженням енергетичних систем, що фрункціонують на основі відновлювальних джерел енергії, зокрема, на основі енергії Сонця. Нерівномірність надходження сонячного випромінювання протягом дня, місяця, року потребує обов'язкового використання теплових акумуляторів, які забезпечують безперебійну роботу сонячних енергетичних пристроїв. Ґрунтові та водяні акумулятори теплоти, принцип дії яких базується на акумулюванні тепла за рахунок теплоємності, знайшли широке застосування у низькотемпературних сонячних установках, що використовуються для гарячого водопостачання та опалення. Для високотемпературних сонячних енергетичних пристроїв такий тип акумулювання $\epsilon$ неефективним та досить коштовним, бо потребує значних об'ємів та площ. У високотемпературних енергетичних системах акумулювання здійснюється за рахунок теплоти фазового переходу «тверде тіло - рідина». Фазоперехідні акумулятори проектуються під відповідний температурний рівень, що дорівнює температурі фразового переходу обраного теплоакумулюючого матеріалу (ТАМ), тому можуть використовуватись не тільки для високотемпературних, а і для низькотемпературних систем в разі налаштування їх під визначений ТАМ. Загальна ефективність фазоперехідного методу акумулювання обумовлена тим, що для багатьох речовин значення ентальпії фазового переходу значно вище теплоутримання за рахунок тепло- 
ємності, тому при однакових геометричних розмірах теплові акумулятори «тверде тіло - рідина» мають значно більшу енергетичну ємність.

Пошук оптимального співвідношення між енергетичними, геометричними та динамічними параметрами фазоперехідного теплоакумулятора неможливий без моделювання температурних полів всередині шару TAM, де поглинається або виділяється прихована теплота фразового переходу. Цей процес супроводжується рухом границі розподілу фаз, на якій температура дорівнює температурі фазового переходу ТАМ. Подібні нелінійні та нестаціонарні задачі в математичній фізиці об'єднують в окремий клас, що має назву задач Стефана. Відомо, що точний аналітичний розв'язок для задач Стефана можна отримати лише в одновимірному випадку при тривіальних граничних умовах [3], тому числові методи є основним інструментарієм для пошуку адекватних розв'язків багатовимірних задач при граничних умовах, що наближені до реальних. Серед таких методів виділяється метод «Mushy Layer» [7], що базується на згладжуванні переходу між твердою та рідкою фазами, де має місце стрибкоподібна зміна параметрів. Саме такий метод було обрано в даній роботі для моделювання фазового переходу в теплоакумуляторі сонячної термодинамічної установки.

Аналіз останніх досліджень і публікацій. На даний момент існує велика кількість наукових робіт, присвячених розв'язанню задачі Стефана наближеними аналітичними та числовими методами. Так, наближений аналітичний розв'язок задачі про фазовий перехід було отримано в [1] на основі енергетичних балансових співвідношень. У [6] вперше було отримано наближений аналітичний розв'язок задачі Стефрана методом Гальоркіна. Ці та інші наближені методи [5] дають швидкі адекватні розв'язки, які зручно використовувати для оцінки параметрів на початкових етапах проєктування, але остаточні рекомендації можна видати лише на основі детального аналізу процесу фазового переходу на основі моделювання задачі Стефана в повній постановці та її числової реалізації.

Проведений огляд підходів до розв'язання задачі Стефана показав, що вибір числового методу, як правило, обумовлюється особливостями протікання процесу фазового переходу, геометрією системи, теплофізичними та динамічними властивостями ТАМ. Так, у [8], де важливим було врахування конвекції в рідинній фазі, числовий розв'язок отримано методом малого параметру. Авторам [2] був відомий закон руху границі розподілу фаз, тому для визначення розподілу температур при фазовому переході було обрано метод вирівнювання фронтів. Для подолання розрахункових труднощів під час дослідження задачі Стефана часто використовуються підстановки Кірхгоффра, Гудмєна, Больцмана, метод змінних часових кроків, метод дрібних кроків та ін. [7, 11, 12].

Особливість протікання процесу фазового переходу в щілинному тепловому акумуляторі сонячної термодинамічної установки обумовлює вибір методу «Mushy Layer», як найбільш ефективного та такого, що відповідає фрізичній моделі явища. 
Метою роботи $є$ побудова математичної моделі фразового переходу «тверде тіло - рідина» в щілинному накопичувачі тепла сонячної термодинамічної установки, створення відповідного числового алгоритму та проведення числового дослідження по визначенню температурних полів в ТАМ, що дозволить розрахувати основні проектні параметри для теплового акумулятора заданої ємності.

Розробка математичної моделі фазового переходу «тверде тіло - рідина». Класична математична модель задачі Стефана містить два рівняння теплопровідності з нелінійною умовою спряженості на границі фразового переходу, де виділяється або поглинається теплота фазового переходу [3]. Наявність розриву теплофрізичних параметрів на границі розподілу фаз спонукає до пошуку різноманітних моделей їх згладжування та переходу до визначення безперервних фрункцій температур не тільки в кожній фази, а і у всьому шарі, де здійснюється фазовий перехід. Одним 3 найпоширеніших методів такого згладжування, якій найбільш наближений до реальної фрізичної суті явища $є$ метод «Mushy Layer» [7]. Він заснований на припущені, що прихована теплота фазового переходу виділяється не в нескінченно тонкому шарі на границі фазового переходу, а в тонкому шарі скінченної товщині, який рухається в часі. Це припущення базується на багаточисельних експериментальних даних, наведених в роботах, що присвячені дослідженню розплавів матеріалів різної природи. Спостереження вказують на існування двофазної зони кристалізації, яка являє собою суміш кристалів різних форм 3 ще незатверділим розплавом. Таким чином, у речовині, що змінює агрегатний стан, виділяють не дві, а три зони: рідка фраза, двофазна зона кристалізації (mushy layer), тверда фраза (рис. 1). Границі цих зон визначаються температурами ліквідуса $T_{\pi}$ та солідуса $T_{c}$, які знаходяться у відповідності до діаграми стану речовини, що розглядається.

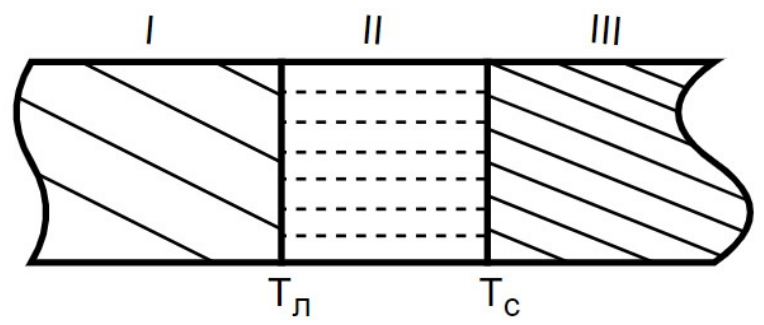

Рис. 1 - Схема затвердіння теплоакумулюючого матеріалу:

I - рідка фаза, II - двофазна зона кристалізації, III - тверда фаза

Наведене припущення дозволяє спростити загальну постановку задачі Стефана, що містить систему рівнянь у часткових похідних зі спеціальною граничною умовою на межі розподілу фраз, де поглинається чи виділяється теплота фразового переходу. Після відповідних перетворень задача описується єдиним диференціальним рівнянням, яке має вигляд: 


$$
c(T) \rho(T) \frac{\partial T}{\partial t}=\operatorname{div}(\lambda \operatorname{grad} T)+q(T),
$$

де $T$ - температура $(K) ; t$ - час $(c) ; c(T)$ - питома теплоємність $(Д ж / \kappa 2 \cdot K) ; \lambda$ - коефіцієнт теплопровідності $(B m \cdot M / K) ; \rho$ - густина $\left(\kappa 2 / \mathrm{M}^{3}\right) ; q$ - функція джерела $\left(\mathrm{Bm} / \mathrm{M}^{3}\right)$.

В якості функції джерела використовується комплекс

$$
q(T)=L \rho_{\phi}\left\{\begin{array}{ll}
\psi(T), & T_{c} \leq T \leq T_{\pi}, \\
0, & T>T_{\pi} m a
\end{array} \quad T<T_{c},\right.
$$

де $L$ - прихована теплота фазового переходу (Дж/кг); $\psi-$ відносна доля твердої фрази в двофазній зоні.

Підставляючи $q(T)$ в рівняння (1) можна спостерігати, що $c(T)$ та $q(T)$ входять в це рівняння однаковим чином. Тому, після проведення відповідних перетворень, отримаємо рівняння (1) у вигляді:

$$
c_{\ni} \rho_{\ni} \frac{\partial T}{\partial t}=\lambda_{\ni}\left(\frac{\partial^{2} T}{\partial x^{2}}+\frac{\partial^{2} T}{\partial y^{2}}+\frac{\partial^{2} T}{\partial z^{2}}\right),
$$

де

$$
\begin{gathered}
c_{\ni}= \begin{cases}c_{p}, & T>T_{\pi}, \\
\frac{c_{p}+c_{m}}{2}-L \frac{d \psi}{d T}, & T_{c}<T<T_{\pi}, \\
c_{m}, & T<T_{c},\end{cases} \\
\rho_{\ni}= \begin{cases}\rho_{p}, & T>T_{\pi}, \\
\frac{\rho_{p}+\rho_{m}}{2}, & T_{c}<T<T_{\pi}, \\
\rho_{m}, & T<T_{c},\end{cases} \\
\lambda_{\ni}= \begin{cases}\lambda_{p}, & T>T_{\pi}, \\
\frac{\lambda_{p}+\lambda_{m}}{2}, & T_{c}<T<T_{\pi}, \\
\lambda_{m}, & T<T_{c},\end{cases}
\end{gathered}
$$


Вирази (3) - (5) містять значення теплоємності, густини та коефіцієнту теплопровідності рідної фази $c_{p}, \rho_{p}, \lambda_{p}$ та твердої фази $c_{m}$, $\rho_{m}, \lambda_{m}$, відповідно. Похідна $-\frac{d \psi}{d T}$ характеризує темп кристалізації, величина якого вибирається, виходячи з уявлень про характер кристалізації відповідного матеріалу. Зокрема, якщо лінії солідуса та ліквідуса ТАМ мають вид прямих паралельних ліній, то темп кристалізації можна виразити аналітичної формулою виду (7):

$$
-\frac{d \psi}{d T}=1 /\left(T_{\pi}-T_{c}\right)
$$

Проведені в [10] експерименти вказують на те, що більшість ТАМ мають самі такі лінії ліквідуса та солідусу.

Теплофізичниі властивості теплоакумулюючого матеріалу. Критерієм для вибору ТАМ $є$ температурний рівень, на якому функціонує система перетворення енергії. Наразі, існує багато природних та синтетичних речовин, що охоплюють великий діапазон температур фразового переходу, які теоретично можна використовувати в якості ТАМ. До низькотемпературних ТАМ відносяться парафіни різного хімічного складу, композиційні матеріали, інші хімічні сполуки, температура фазового переходу яких $T_{\phi} \leq 80^{\circ} \mathrm{C}$. Середньотемпературні ТАM $\left(T_{\phi} \leq 900^{\circ} \mathrm{C}\right)$ - це різноманітні органічні матеріали, солі та їх суміші, неорганічні хімічні сполуки та їх композиції. Діапазон температур фазового переходу високотемпературних ТАМ типу кремнію, фториду або гідриду літію, фториду натрію та ін. починається $3 T_{\phi}>900^{\circ} \mathrm{C}$. Крім температури фразового переходу при виборі ТАМ важливим $€$ його теплофрізичні властивості, екологічна та економічна складова. Таким критеріям повністю відповідають солі лужних металів, які широко застосовуються при акумулювання енергії в діапазоні температур від $400 \mathrm{~K}$ до $900 \mathrm{~K}$. Саме в такому температурному діапазоні функціонують сонячні термодинамічні станції з параболоциліндричними концентраторами, обов'язковим елементом яких є фразоперехідний теплоакумулятор [13].

Евтектична суміш нітрату натрію $\mathrm{NaNO}_{3}$ та калію $\mathrm{KNO}_{3}$ у співвідношенні $45,67 \%$ та $54,33 \%$ є найбільш розповсюдженим ТАМ для подібних станцій. Слід відмітити, що такі нітратні суміші в сонячних термодинамічних установках можуть використовуватися не тільки як ТАМ, але і як теплоносій [15]. Саме така суміш досліджувалась в якості ТАМ в даній роботі.

Незважаючи на те, що евтектична суміш нітрату натрію та калію $є$ популярним ТАМ, у відкритій літературі наводяться досить суперечливі дані щодо їх теплофізичних властивостей. На основі літературних джерел $[4,10,14]$ було проведено аналіз цих властивостей та прийняті відповідні адитивні значення теплофрізичних параметрів, які наведені в табл. 1. 
Таблиця 1 - Теплофізичні параметри

\begin{tabular}{|c|c|c|c|}
\hline Параметр & Значення & Параметр & Значення \\
\hline$\rho_{m}, \frac{\kappa 2}{\mu^{3}}$ & 1900 & $\lambda_{p}, \frac{B m \cdot M}{K}$ & 0.425 \\
\hline$\rho_{p}, \frac{\kappa 2}{\mu^{3}}$ & 2100 & $\lambda_{m}, \frac{B m \cdot M}{K}$ & 0.5 \\
\hline$c_{p}, \frac{\text { Дж}}{\kappa 2 \cdot K}$ & 1800 & $L, \frac{\text { Дж}}{\kappa 2}$ & $232.5 \cdot 10^{3}$ \\
\hline$c_{m}, \frac{\text { Дж}}{\kappa 2 \cdot K}$ & 1400 & $T_{\pi}, K$ & 496 \\
\hline
\end{tabular}

Числова реалізація, результати та обговорення. На основі математичної моделі (2) - (6) було створено числовий алгоритм, який реалізовано на мові програмування Python. При складанні числового алгоритму важливе значення мав вибір кількості кроків за просторовою координатою. Це пов'язано з особливістю розв'язання задачі Стефана методом "Mushy Layer", а саме, в перехідну зону, яка обмежена температурами $T_{\pi}$ і $T_{c}$, повинні потрапити мінімум 10 вузлів розрахункової сітки, щоб забезпечити врахування прихованої теплоти фазового переходу. Стійкість розрахункової схеми для задачі з особливими умовами, що пов'язані з виділенням чи поглинанням тепла, забезпечувалась вибором відповідної кількості кроків за часом і співвідношенням їх величини з величиною кроків за просторовою координатою.

Для реалізації числового експерименту була обрана фрізична модель щілинного теплового акумулятору з шаром ТАМ товщиною $l=0,2 \mathrm{M}$. Повний час числового експерименту дорівнював $\tau=5$ год. Діапазон температур ліквідуса та солідуса був вибраний у відповідності до температури фразового переходу и дорівнював $T_{л}=496 \mathrm{~K}$ та $T_{c}=494 \mathrm{~K}$.

На рис. 2 представлені результати числового моделювання процесу фазового переходу «тверде тіло - рідина» в евтектичній суміші солей натрію та калію при граничних умовах першого роду. Початкова температура ТАМ дорівнювала $T_{m}=330 \mathrm{~K}$, а температура стінки теплового акумулятора $-T_{c m}=1650 \mathrm{~K}$. На графіку можна чітко спостерігати формування границі розподілу фраз, ії̈ рух в часі, розподіл температур в рідкій та твердий фазі, товщину шару розплавленого або затверділого TAM. Якісна картина процесу співпадає 3 відомими класичними розв'язками задачі Стефрана [3].

Більш характерним режимом фунціонування теплового акумулятора $€$ режим, що відповідає граничним умовам третьего роду. Розв'язок задачі Стефана з граничними умовами третього роду при початковій температурі $T_{m}=330 \mathrm{~K}$, коефіцієнті тепловіддачі $\alpha=1000 \mathrm{Bm} / \mathrm{m}^{2} \cdot \mathrm{K}$ та температурі теплоносія $T_{m \mu}=2650 \mathrm{~K}$, наведений на рис. 3 . 


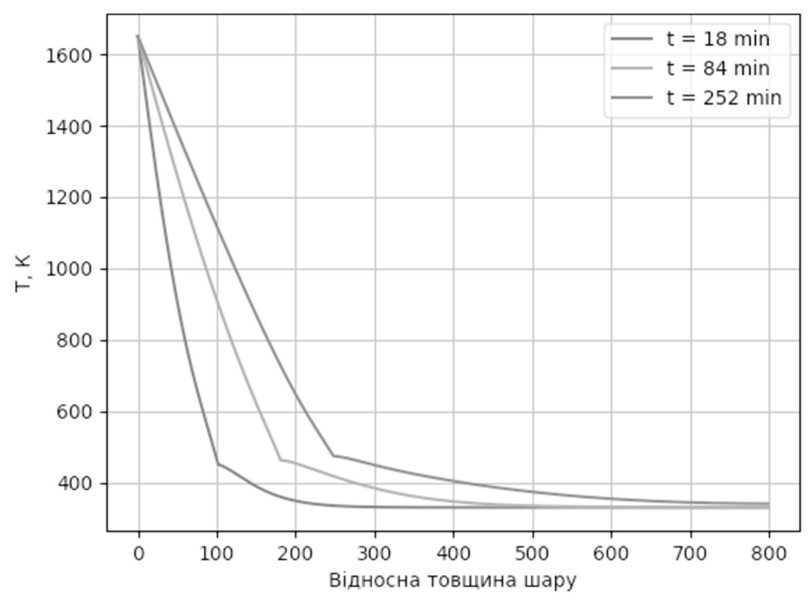

Рис. 2 - Розподіл температури у шарі ТАМ при граничних умовах першого роду

Як видно з рис. 3, в цілому, якісна картина процесу фразового переходу співпадає з попереднім випадком, що опосередковано свідчить про адекватність розробленої математичної моделі та відповідного числового алгоритму. Більш точна кількісна верифікація буде отримана на наступних етапах дослідження відповідної суміші солів шляхом порівняння з експериментальними даними або розв'язками, що отримані іншими методами.

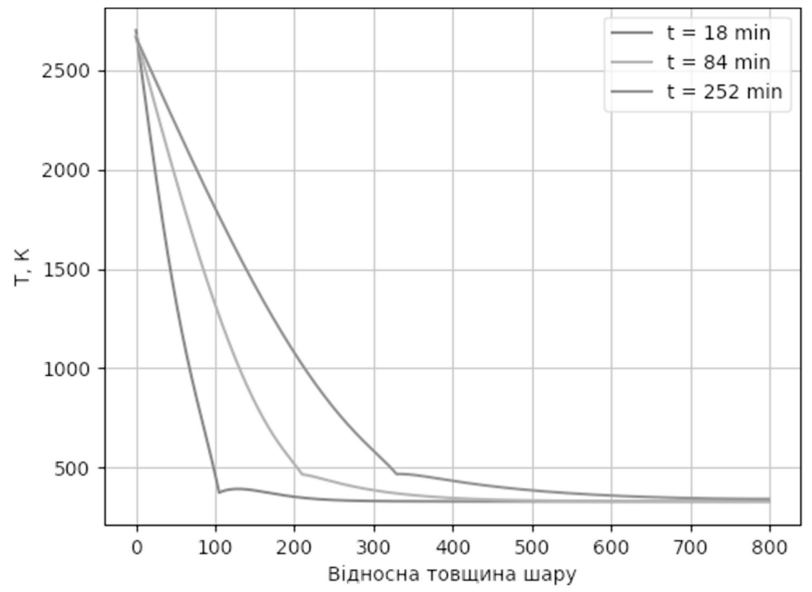

Рис. 3 - Розподіл температури у шарі ТАМ при розв'язанні задачі Стефана з граничними умовами третього роду 
Висновки. Наведені в роботі результати відображають перший етап дослідження перспективних теплоакумулюруючих матеріалів, використання яких може забезпечити безперебійну роботу системи перетворення сонячних термодинамічних установок, що функціонують в середньотемпературному інтервалі. Аналіз різних підходів до розв'язання задачі Стефана дозволив визначити метод «Mushy Layer» таким, що відповідає суті фрізичного процесу в фазоперехідному тепловому акумуляторі. Побудована на основі вибраного методу математична модель та проведені числові розрахунки дозволили виявити особливості протікання процесу фазового переходу, визначити розподіл температур в рідкій та твердій фазі, товщину шару розплавленого або затверділого теплоакумулюруючого матеріалу, швидкість руху границі розподілу фаз.

\section{БІБЛІОГРАФІЧНІ ПОСИЛАННЯ}

1. Кныш Л.И. Математическое моделирование процессов теплообмена в аккумулирующих системах «твёрдое тело - жидкость» // Пром. теплотехніка. 2014. T. 36. № 4. С. 5-10.

2. Кобилянська О.Б. Задача Стефана зі змінним у часі джерелом тепла // Вісник Харківського нац. ун-ту. 2012. № 1015. С.167-172.

3. Лыков А.В. Теория теплопроводности. М.: Высшая школа, 1967. 600 с.

4. Назиров Р.A. Материалы с изменяющимся фазовым состоянием в ограждающих конструкциях. // Строительство и реконструкция. 2019. № 6 (86) С. 66-85.

5. Пехович А.И., Жидких В.М. Расчёты теплового режима твердых тел // Л.: Энергия, 1976. 352 с.

6. Подгородный A.P. Численный анализ фазовых превращений на примере одномерной задачи // Радиоэлектроника и информатика. 2015. № 2. С. 45-48.

7. Тимошпольский В.И., Беляев Н.М., Рядно А.А. и др. Прикладные задачи металлургической теплофизики. Мінск: Навука і тэхніка, 1991. 320 с. ISBN 5-34300826-7.

8. Шевченко А.И. Задача Стефана при наличии конвекции // Доповіді Нац. акад. наук України. 2012. № 1. С. 25-29.

9. Caldwell J., Kwan Y. A brief review of several numerical methods for onedimensional Stefan problems // Thermal Science. 2009. Vol. 13. No 2. P. 61-72.

10. D'Aguanno B., Karthik M., Grace A. N., Floris A. Thermostatic properties of nitrate molten salts and their solar and eutectic mixtures // Scientific reports. 2018. Vol. 8. No 10485. P. 1-13.

11. Gupta S.C. The Classical Stefan Problem. Basic Concepts, Modelling and Analysis with Quasi-Analytical Solutions and Methods. Amsterdam: Elsevier; 2018. 732 p.

12. Javierre-Perez E. Literature Study: Numerical Methods for solving Stefan problems // Report 03-16, Delft University of Technology. 2003. P. 35-45.

13. Knysh $\mathbf{L}$. Comprehensive mathematical model and efficient numerical analysis of the design parameters of the parabolic trough receiver // International Journal of Thermal Sciences. 2021. Vol.162. No 106777. P. 1-15.

14. Liu M, Saman W., Bruno F. Review on storage materials and thermal performance enhancement techniques for high temperature phase change thermal storage systems // Renewable and Sustainable Energy Reviews. 2012. Vol. 16, Iss. 4. P. 2118-2132. https://habr.com/ru/post/102753/ 


\author{
И. В. Гарькавский, Л. И. Кныш, д-р техн. наук \\ МОДЕЛИРОВАНИЕ ЭНЕРГОПЕРЕНОСА \\ В ФАЗОПЕРЕХОДНОМ ТЕПЛОАККУМУЛЯТОРЕ \\ СОЛНЕЧНОЙ ТЕРМОДИНАМИЧЕСКОЙ УСТАНОВКИ
}

Проведено численное исследование процессов фазового перехода «твердое тело-жидкость» в тепловом аккумуляторе солнечной термодинамического установки. В основе математической модели и численного алгоритма положен метод "Mushy Layer", который отражает физическую суть явления. Компьютерное моделирование задачи Стефана позволило выявить особенности процесса фазового перехода, определить распределение температур в жидкой и твердой фазе, толщину твердой и жидкой фаз теплоаккумулирующего материала, скорость движения границы раздела фаз.

Ключевые слова: тепловой аккумулятор; задача Cтефрана; метод «Mushy Layer»; теплоаккумулирующий материал; численные эксперименты.

UDC 519.63

\author{
I. V. Harkavskyi, L. I. Knysh, Dr. Sci. (Tech.) \\ MODELING OF ENERGY TRANSFER \\ IN A PHASE-CHANGE THERMAL STORAGE MODULE \\ OF A SOLAR THERMODYNAMIC POWER PLANT
}

A numerical study of the phase change "solid-liquid" processes in the thermal storage module of a solar thermodynamic power plant is carried out. The mathematical model and numerical algorithm are based on the "Mushy Layer" method, which reflects the physical essence of the phenomenon. Computer modeling of the Stefan problem allows to reveal the phase-change process features, to determine the temperature distributions in the liquid and solid phases, the thickness of the solid and liquid phases in the thermal storage material, the velocity of the phase boundary.

Keywords: thermal storage module; Stefan problem; "Mushy Layer" method; thermal storage materials; numerical experiments.

Thermal storage systems are key elements of solar thermodynamic systems, since guarantee smooth functioning power plants when the Sun is absent. Phase-change thermal storage systems have significant advantages in comparison with other methods of thermal storage. Thermal storage systems are designed on temperature level which corresponds phase change temperature of the chosen thermal storage material. Therefore, using of a molten salt is widespread technology of thermal storage in solar thermodynamic systems. Eutectic mixture of sodium nitrate and potassium nitrate as phase change material for solar thermodynamic plants is numerically studied in the present article. Numerical algorithm based on mathematical model that is composed by the "Mushy Layer» method. The choice of this method is due to nature of the phase-change process in the molten-salt thermal storage modules. Applying of the "Mushy Layer" method allows to simplify Stefan problem and to replace two partial differential equations by single heat equation for solid, liquid and "Mushy" phases. Such equation is numeri- 
cally solved assuming that solidus line and liquidus line of the phase-change material are parallel. This assumption allows to find analytical equation for crystallization rate and to take into account latent heat of fusion (melting). The thermodynamic parameters of the eutectic mixture of sodium nitrate and potassium nitrate is chosen vie review and analysis of numerous scientific sources. The developed numerical algorithm is realized using Python inhouse software and tested using classical heat equation without phase change. Computer modeling of the phase transition in plate thermal storage of the solar thermodynamic plants allows to identify features of the phasechange process, to determine the temperature distributions in the liquid and solid phases, thickness of the solid and liquid phases in the thermal storage material, the velocity of the phase boundary.

\section{REFERENCES}

1. Knysh L.I. Mathematical modeling of heat transfer processes in accumulating systems "solid - liquid" // Ind. heat engineering. 2014. Vol. 36., № 4. P. 5-10. (in Russian).

2. Kobylyanska O.B., Lyashenko V. P. Stefan's problem with a time-varying heat source // Vestnik of Kharkiv National University. 2012. № 1015. P.167-172. (in Russian).

3. Lykov A. V. Thermal conductivity theory // M.: Vysshaya shkola, 1967. 600 p. (in Russian).

4. Nazirov R.A., Takhtobin A. V. Materials with a changing phase state in enclosing structures // Construction and reconstruction. 2019. № 6 (86.) P. 66-85. (in Russian).

5. Pekhovich A. I., Zhidkikh V.M. Calculations of the thermal mode of solids. Leningrad: Energia, 1976. 352 p. (in Russian).

6. Podgorodnyi A.R., Sidorov M.V., Yalovega I.G. Numerical analysis of phase transformations on the example of a one-dimensional problem // Radioelectronics and Informatics. 2015. No 2. P. 45-48. (in Russian).

7. Tymoshpolskyi V.I., Belyaev N.M., Ryadno A.A. and etc/ Applied problems of metallurgical thermal physics. Minsk: Navuka i tekhnika, 1991, 320 c. ISBN 5-343-00826-7. (in Russian).

8. Shevshenko A. I., Minenko A.S. Stefan problem in the presence of convection // Reports of the National Academy of Sciences of Ukraine. 2012. №1. P. 25-29. (in Russian).

9. Caldwell J., Kwan Y. A brief review of several numerical methods for onedimensional Stefan problems // Thermal Science. 2009. Vol. 13. No 2. P. 61-72.

10. D'Aguanno B., Karthik M., Grace A. N., Floris A. Thermostatic properties of nitrate molten salts and their solar and eutectic mixtures // Scientific reports. 2018. Vol. 8. No 10485. P.1-15.

11. Gupta S.C. The Classical Stefan Problem: Basic Concepts, Modelling and Analysis with Quasi-Analytical Solutions and Methods. Amsterdam: Elsevier; 2018. 732 p.

12. Javierre-Perez E. Literature Study: Numerical Methods for solving Stefan problems // Report 03-16, Delft University of Technology. 2003. P. 35-45.

13. Knysh L. Comprehensive mathematical model and efficient numerical analysis of the design parameters of the parabolic trough receiver // International Journal of Thermal Sciences. 2021. Vol.162. No 106777. P. 1-13.

14. Liu M, Saman W., Bruno F. Review on storage materials and thermal performance enhancement techniques for high temperature phase change thermal storage systems // Renewable and Sustainable Energy Reviews. 2012. Vol. 16. Iss. 4, P. 2118-2132. https://habr.com/ru/post/102753/.

\footnotetext{
Дніпровський національний університет імені Олеся Гончара, Дніпро, Україна
} 